\title{
NBSIR 80-2078
}

\section{The NBS Gage Block Calibration Process Using A Measurement Assurance Program}

Clyde D. Tucker

Automated Production Technology Division

Center for Mechanical Engineering

and Process Technology

National Engineering Laboratory

National Bureau of Standards

U.S. Department of Commerce

Washington, D.C. 20234

June 1980

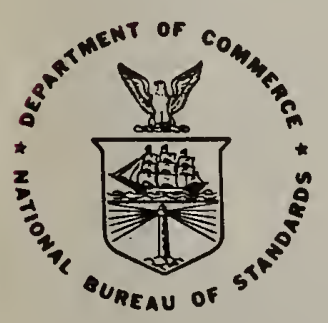

100

.456

$80-2078$

1980

U.S. DEPARTMENT OF COMMERCE

NATIONAL BUREAU OF STANDARDS 

THE NBS GAGE BLOCK CALIBRATION PROCESS USING A MEASUREMENT ASSURANCE PROGRAM

ASSURANCE PROGRAM

Clyde D. Tucker

\author{
Automated Production Technology Division \\ Center for Mechanical Engineering \\ and Process Technology \\ National Engineering Laboratory \\ National Bureau of Standards \\ U.S. Department of Commerce \\ Washington, D.C. 20234
}

June 1980

U.S. DEPARTMENT OF COMMERCE, Philip M. Klutznick, Secretary Luther H. Hodges, Jr., Deputy Secretary Jordan J. Baruch, Assistant Secretary for Productivity, Technology, and Innovation NATIONAL BUREAU OF STANDARDS, Ernest Ambler, Director 

THE NBS GAGE BLOCK CALIBRATION PROCESS

USING A MEASUREMENT ASSURANCE PROGRAM

\section{INTRODUCTION}

This is a refort covering the sequence of operations used to assign length values to the blocks identified on the title page of the NBS Gage Block Calibration Report. It includes a brief description of the measurement methods and procedures, including process control, a list of publications pertaining to gage blocks, and a discussion of the systematic and random components of error affecting the measuring process.

The blocks have been divided into groups, to facilitate ease of handling, as follows:

$\begin{array}{lrccrl}\text { Group } & \text { I } & \text { Less } & \text { Than } & 0.100 & \text { in } \\ \text { Group } & \text { II } & 0.100 & \text { to } & 0.107 & \text { in } \\ \text { Group } & \text { III } & 0.108 & \text { to } & 0.126 & \text { in } \\ \text { Group } & \text { IV } & 0.127 & \text { to } & 0.146 & \text { in } \\ \text { Group } & \text { V } & 0.147 & \text { to } & 0.500 & \text { in } \\ \text { Group } & \text { VI } & 0.550 & \text { to } & 4.000 & \text { in } \\ \text { Group } & \text { VII } & 5.000 & \text { to } & 20.000 & \text { in }\end{array}$

In the calibration report the assigned deviations from the nominal lengths, their associated uncertainties which are a combination of the systematic and random errors of the process, and the coefficients of thermal expansion (assumed or measured as noted) are presented. In the appendix of the calibration report, the statistical information shown becomes a part of the collection of data used to characterize the NBS measurement process. Such a collection has been used to establish the control limits for surveillance of the measurement process and to give assurance of validity of statements about these measurements. These collections are open for inspection at our facility. It is presumed that these blocks will be used in a similarly well-characterized measurement process so that the statistical parameters of both processes can be combined to provide a realistic estimate of the uncertainty of the length unit as actually realized in another facility. A comprehensive service directed toward such an evaluation is part of a Length Measurement Assurance Program of the National Bureau of Standards.

\section{LENGTH MEASUREMENT}

The blocks covered by this report were cleaned and lightly "stoned" to remove surface imperfections which might interfere with the measurement. Since "gaging" surfaces are neither flat nor parallel, it is felt that the most important attribute of the block is the ability to be made to adhere closely to appropriate surfaces (i.e., wring). Where it is felt that quantitative estimates of the degree of "flatness and parallelism" are required, it is suggested that acceptance tests be performed at the point of usage [1]. 
The length values assigned to the blocks in this report are with reference to the values assigned to master gage blocks of NBS. The reference values have been established by an interferometric measurement process and are the lengths of a line normal to an auxiliary plane in close proximity of the surface to a defined "gaging" point. " $\mathrm{X}$ " on the opposite surface. For location of the point, $\mathrm{X}$, relative to the nominal size marking see the accompanying figure.

\section{INTERCOMPARISON DESIGN}

A procedure that is statistically designed to eliminate the effects of short term thermal and electronic drift is used with four blocks of the same nominal size, two reference and two "unknowns" according to the following design [2]:

\begin{tabular}{cr} 
Observation & Difference Mea \\
\hline$Y(1)$ & $S .-S$. \\
$Y(2)$ & $Y-S$. \\
$Y(3)$ & $X-Y$ \\
$Y(4)$ & $S . .-X$ \\
$Y(5)$ & $S . .-Y$ \\
$Y(6)$ & $Y-S$. \\
$Y(7)$ & $S .-X$ \\
$Y(8)$ & $X-S .$.
\end{tabular}

The symbols (S.) and (S..) indicate reference blocks, listed by serial number in the body of the report. (X) and (Y) designate "unknown" blocks, one set of which is covered by this report, and the other covered by test numbers stated in the appendix to the report.

In such an intercomparison, only differences in length can be measured. Because of the limited range of present electro-mechanical comparators, [3] al1 blocks in a given comparison are of the same nominal value. A redundancy in the number of measurements (eight measurements to determine four values) provides a means for checking on the precision of the process by the method of least squares using the sum of the lengths of the two reference blocks, $\left[\left(S_{.}\right)+\left(S_{. .}\right)\right]$, as the restraint. The least squares estimate of the difference between the reference blocks for this calibration is an independent estimate of the difference, and serves as a "check standard".

\section{PROCESS CONTROL}

The standard deviation, as computed from the least squares solution, provides a check on the short term, or "within-run" process precision. This value is compared with the long run pooled value of these standard deviations designated as the accepted within-run standard deviation of the process for the group.

The estimates of the check standards provide a sequence of values that realistically reflect the totality of variations which beset measurements of test items. The standard deviation of this collection of values is the total process standard deviation. 
If the "within-run" standard deviation and the values for the check standard come from a stable measurement process, and if the statistical tests for these two parameters from this calibration show them to be in agreement with their accepted values; then, one takes this as evidence that the process is in a state of control, and the uncertainty statements are valid.

An intercomparison run is repeated, when the statistical tests for either the "within-run" standard deviation or the check standard value fails. Should the repeated run fail again, the gage blocks are re-examined for defects, i.e. scratches, burrs or unclean surfaces or malfunctioning comparator.

\section{SYSTEMATIC ERRORS IN GAGE BLOCK MEASUREMENT}

When using gage blocks in practical measurement, two factors may introduce systematic errors into the results: dissimilarity of material and deviation of temperature from $20^{\circ} \mathrm{C}$.

Length values can be assigned to other like blocks by determining the difference in length with a contacting comparator. If the blocks are of dissimilar material, the indicated difference is a function of the force exerted by the comparator probe on the blocks under comparison as well as the elastic properties and surface finish of the blocks, in the immediate vicinity of the point of contact. Data adjustment to compensate for these differences is necessary. [9] If the comparator being used has both a top and bottom contact, the differential penetration for both contacts must be considered. The uncertainty for the reported values includes an allowance for the uncertainty of the differential penetration corrections. When the two blocks are made of the same material and tested by the same probe(s) at the same contact force, no correction is applied.

Al1 measurements for this report were made in a temperature environment in the neighborhood of $20^{\circ} \mathrm{C}$. For groups V and VI, assigned values have been adjusted to exactly $20^{\circ} \mathrm{C}$ (1968 International Practical Temperature Scale) using the stated, or handbook, values for the coefficient of linear thermal expansion. In the comparison process, all blocks are at very nearly the same temperature. Corrections based on differential coefficients of expansion are assumed negligible for blocks of Groups I through VI.

In order to extend the usefulness of the assigned values over a temperature range of $20^{\circ} \mathrm{C}$ to $25^{\circ} \mathrm{C}$, it may be necessary to determine a coefficient of thermal expansion for each block in Groups VI and VII. A procedure has been developed at NBS to measure these coefficients for gage blocks and a report can be requested at an additional charge.

\section{UNCERTAINTY}

The systematic component of the uncertainty of the values in this report is the uncertainty of the master block value from the interferometric determination. The bounds for the effects of random errors in the intercomparisons are taken to be three times the total process standard deviation. 
When the blocks are of different material than the master blocks, a correction is made for differential penetration. The uncertainty for the penetration increases the uncertainty of the reported deviation by one micro-inch. This uncertainty has been determined by statistically controlled experiments at NBS.

The magnitude of systematic errors from sources other than that of the accepted values for the reference blocks is considered negligible at temperatures very nearly $20^{\circ} \mathrm{C}$. It should be noted that the uncertainty reflects the performance of the comparator process used to establish the reported deviations and the uncertainties in the interferometric process.

The uncertainty in assigned value contained in the report becomes a systematic error for the length measurements of the user. In the absence of other significant systematic effects in the user's measurement process (a condition which must be demonstrated) the uncertainty of the value assigned by the user is an appropriate combination of the systematic error in the standard and the random component associated with his process. If the measurement processes are in control and appropriate uncertainties are assigned, the values produced by different measurement facilities will have overlapping uncertainty bands. One cannot discuss differences in values for the same object obtained by different facilities with any degree of seriousness unless each value is accompanied by a realistic uncertainty statement.

The author wishes to acknowledge the contributions of $\mathrm{Mr}$. Joseph M. Cameron and Mr. Paul E. Pontius in the development of the NBS Gage Block Measurement Assurance Program. This paper is the result of their original work. 
Publications pertaining to gage blocks that are available from the Superintendent of Documents, U.S. Government Printing Office, Washington, D.C. 20402 or the National Bureau of Standards, Washington, D.C. 20234.

1) Gage Block Flatness and Parallelism Measurement, J. S. Beers and C. D. Tucker, NBSIR 72-239, August 1973. SD Cat. No. C13.

2) Designs for the Calibration of Small Groups of Standards in the Presence of Experimental Drift. J. M. Cameron and G. E. Hailes, NBS Tech Note 844, August 1974.

3) Preparations for Gage Block Comparison Measurements, C. D. Tucker, NBSIR 74-523, July 1974. SD Cat. No. C13.

4) A Gage Block Measurement Process Using Single Wavelength Interferometry, J. S. Beers, NBS Monograph 152, December 1975. SD Cat. No. C13.44:152.

5) The Measurement Assurance Program - A Case Study in Length Measurements, Part 1. Long Gage Blocks ( 5 inch to 20 inch) Paul E. Pontius, NBS Monograph 149, November 1975. SD Cat. No. C13.44:149.

6) Intercomparison Procedures for Gage Blocks Using Electromechanical Comparators, J. S. Beers and C. D. Tucker, NBSIR 76-979, January 1976.

7) Fortran Program to Determine Length of Gage Blocks Using Single Wavelength Interferometry, R. N. Varner, NBS Tech Note 956, September 1977. SD Cat. C13.46:956.

8) Measurement Assurance for Gage Blocks, M. Carroll Croarkin, John Beers, and C. D. Tucker, NBS Monograph 163, February 1979. SD Stock No. 003-003-.

9) Contact Deformation in Gage Block Comparisons, J. S. Beers and J. E. Taylor, NBS Technical Note 962, May 1978. SD Stock No. 003-003-. 

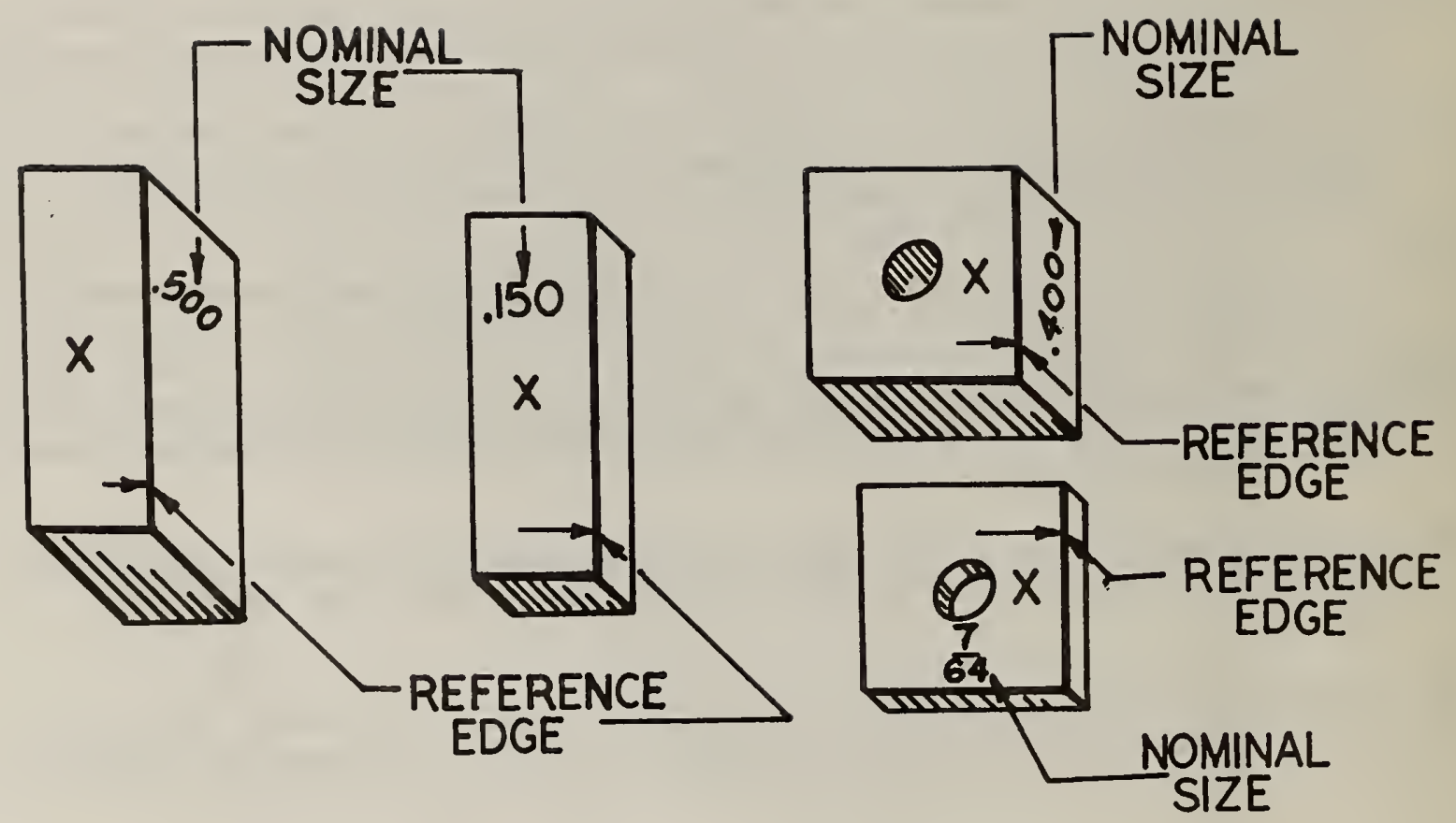
WOS-IILA WEV. HOH

U.S. DEPT. OF COMM.

BIBLIOGRAPHIC DATA SHEET

1. PUBLICATION OR REPORT NO.

NBSIR $\quad 80-2078$

4. TITLE AND SUBTITLE

THE NBS GAGE BLOCK CALIBRATION PROCESS USING A MEASUREMENT ASSURAINCE PROGRAM

7. AUTHOR(S)

Clyde D. Tucker

9. PERFORMING ORGANIZATION NAME AND ADDRESS

NATIONAL BUREAU OF STANDARDS

DEPARTMENT OF COMMERCE

WASHINGTON, DC 20234

12. SPONSORING ORGANIZATION NAME AND COMPLETE ADDRESS (Stroot, City, State, zIP)

13. Type of Report \& Period Covered

1. Sponsoritg Agency Code

15. SUPPLEMENTARY NOTES

Document describes a computer program; SF-185, FIPS Software Summary, is attached.

16. ABSTRACT (A 200-word or loss factual summary of most sigrificant information. If document includes a significant bibliography or literature survey, mention it here.)

The calibration method for gage blocks, employing a measurement assurance program, is described for the user of an NBS calibration report. The various parameters and their significance to the calibration process are discussed.

17. KEY WORDS (six to twelve entries; alphabetical order; capitalize only the first letter of the first key word unless a proper name; separated by semicolons)

Check standard, gage blocks, measurement assurance, random errors, standard deviation, systematic errors, uncertainty.

18. AVAILABILITY

$$
\text { [X] Unlimited }
$$

For Official Distribution. Do Not Release to NTIS

[ Order From Sup. of Doc., U.S. Government Printing Office, Wasinington, DC 20402, SD Stock No. SNÖ03-003-

[X] Order From National Technical Information Service (NTIS), Springfield, VA, 22161

\begin{tabular}{|l|c|}
\hline $\begin{array}{l}\text { 19. SECURITY CLASS } \\
\text { (THIS REPORT) } \\
\text { UNCLASSIFIED }\end{array}$ & $\begin{array}{c}\text { 21. NO. OF } \\
\text { PRINTED PAGES }\end{array}$ \\
\hline $\begin{array}{l}\text { 20. SECURITY CLASS } \\
\text { (THIS PAGE) }\end{array}$ & 8 \\
UNCLASSIFIED & \$2. Price \\
\hline
\end{tabular}




$z$
0
0
0
0
0
1
0
0
0
1
1 